\title{
Penerapan Metode Moora Pada Penilaian Kinerja Tenaga Pegawai Honorer Pada Dinas Ketenagakerjaan
}

\author{
Juni Irna Purba ${ }^{1}$, Muhammad Safii ${ }^{2}$, Iin Parlina ${ }^{3}$ \\ ${ }^{1}$ STIKOM Tunas Bangsa, Pematangsiantar - Indonesia \\ ${ }^{2,3}$ AMIK Tunas Bangsa, Pematangsiantar - Indonesia \\ Jln. Sudirman Blok A No. 1-3 Pematangsiantar, Sumatera Utara \\ ${ }^{1}$ juniirnapurba@gmail.com, ${ }^{2}$ m.safii@amiktunasbangsa.ac.id, \\ 3in@amiktunasbangsa.ac.id
}

\begin{abstract}
The performance assessment of honorary staff at the Manpower Office was conducted on 7 employees. Aiming to carry out performance appraisals in order to help the office or agency to be able to determine the appropriate employees to be elected if there is an appointment that is carried out once in 4 years, then it is carried out for the assessment of the performance of honorary employees. Then we need a system that can help make a decision to assess the performance of honorary staff as a reasonable basis for 4 years in the future to be able to submit an appointment file based on the criteria and the weight value of each predetermined criterion such as, 35\% Attendance, 20\% Work Quality, Work Discipline $20 \%$, Service $25 \%$. So that the ranking results that have been processed using the MOORA algorithm, namely, A1: 0.4139 are eligible to be selected in the performance assessment of the highest number of honorary staff. And A3: 0.4103, A2: 0.4042 and so on.
\end{abstract}

Keywords: Moora Method, Decision Support System, Honorary Staff, Ranking

\begin{abstract}
Abstrak
Penilaian kinerja tenaga honorer di Dinas Ketenagakerjaan dilakukan terhadap 7 orang pegawai. Bertujuan untuk melakaukan penilaian kinerja agar dapat membantu kantor atau instansi untuk dapat menentukan pegawai yang layak untuk dipilih jika ada suatu pengangkatan yang dilakukan secara 4 Tahun sekali, maka dilakukan untuk penilaian kinerja pegawai honorer. Maka dibutuhkan sebuah sistem yang dapat membantu pengambilan suatu keputusan penilaian kinerja tenaga honorer sebagai dasar penentuan yang layak untuk 4 tahun kedepannya dapat untuk melakukan pengajuan berkas pengangkatan berdasarkan kriteria dan nilai bobot setiap kriteria yang telah ditentukan seperti, Kehadiran 35\%, Kualitas Kerja 20\%, Disiplin Kerja 20\%, Pelayanan 25\%. Sehingga hasil perangkingan yang telah diproses dengan menggunakan algoritma MOORA yaitu, A1 : 0,4139 yang layak terpilih dalam penilaian kinerja tenaga pegawai honorer dengan jumlah tertinggi. Dan A3 :0,4103, A2:0,4042 dan seterusnya.
\end{abstract}

Kata Kunci: Metode Moora, Sistem Pendukung Keputusan, Tenaga Pegawai Honorer, Perangkingan

\section{Pendahuluan}

Tenaga honorer yang bekerja di Dinas Ketenagakerjaan berjumlah 7 orang yang memiliki kendala besar yaitu pelaksanaan Penilaian Kinerja Tenaga Honorer. Penilaian kinerja honorer di dinas Ketenagakerjaan melakukan penilaian dengan cara melihat kedisplinan para pegawai honorer mulai dari cara berbicara (komunikasi), kehadiran (absensi), serta penilaian dengan cara pelayanan terbaik ke masyarakat yang membutuhkan suatu Informasi Lowongan Pekerjaan atau Pendaftaran Kerja.Oleh sebab itu sangat diperlukan manajemen sumber daya 
manusia di suatu instasi dengan penilaian kinerja honorer untuk menjadi motivasi para pegawai honorer dalam meningkatkan suatu pekerjaan atau operasional dalam dunia kerja, karena dalam dunia kerja dibutuhkan suatu dorongan atau pemicu agar pegawai memiliki daya kerja yang baik. Sistem pendukung keputusan merupakan sistem yang mampu memberikan kemampuan solusi dalam pemecahan masalah. Sistem ini dapat digunakan sebagai alat bantu pengambilan keputusan [1]. Dalam penelitian ini data yang digunakan berasal dari Dinas Ketenagakerjaan Pematangsiantar. Pengumpulan data dilakukan dengan cara melakukan riset pada Dinas Ketenagakerjaan. Setelah data terkumpul langkah selanjutnya data langsung diolah agar mendapat hasilpenilaian kinerja honorer dengan menggunakan metode Moora.

Metode Moora adalah suatu pengambilan keputusan dengan multi-kriteria, metode ini memiliki tingkat fleksiblitas yang tinggi dan kemudahan dalam memisahkan bagian subjektif dari suatu proses evaluasi ke dalam kriteria bobot keputusan dengan beberapa atribut pengambilan keputusan [2] .Selain itu, metode moora juga memiliki tingkat selektifitas yang baik karena dapat menentukan tujuan dari kriteria yang bertentangan yang mana kriteria dapat bernilai menguntungkan (benefit) atau yang tidak menguntungkan (cost). Pada penelitian [3] yang mengangkat judul "Sistem Pendukung Keputusan Kinerja Tenaga Honorer Di Dinas Pekerjaan Umum Dan Energi Sumber Daya Mineral Kabupaten Klaten" memiliki hasil pengujian yang berhasil dilakukan.dan secara fungsional sistem sudah dapat menghasilkan output yang sesuai. Dalam penilaian kinerja tenaga kerja honorer terdapat beberapa kriteria yang menjadi landasan bagi perusahaan seperti Kehadiran, Kualitas Kerja, Disiplin kerja, Pelayanan. Dengan adanya kriteria maka akan lebih mudah untuk dapat menentukan peneliaan kinerja tenaga honorer.

\section{Metodologi Penelitian}

\subsection{Tenaga Honorer}

Tenaga honorer adalah seorang yang diangkat oleh pejabat pembina kepegawaian atau pejabat lain dalam pemerintahan untuk melaksanakan tugas tugas tertentu pada instansi pemerintah atau yang penghasilannya menjadi beban APBN/APBD.Penilaian kinerja honorer di Dinas Ketenagakerjaan melakukan penilaian dengan cara melihat kedisplinan para pegawai honorer mulai dari cara berbicara(komunikasi), kehadiran(absensi), serta penilaian dengan cara pelayanan terbaik ke masyarakat yang membutuhkan suatu Informasi Lowongan Pekerjaan atau Pendaftaran Kerja [4].

\subsection{Sistem Pendukung Keputusan}

Sistem Pendukung Keputusan yaitu sistem informasi yang interaktif dalam menyediakan suatu informasi untuk membantu dalam pengambilan keputusan dalam keadaan yang semi terstruktur dan tidak terstruktur, dimana secara pasti tidak seorang pun tahu bagaimana seharusnya keputusan dibuat [5-6].

\subsection{MOORA (Multi ObjectiveOptimization on the Basis of RatioAnalysis)}

Metode MOORA memiliki tingkat fleksibilitas dan kemudahan untuk dipahami dalam memisahkan bagian subjektif dari suatu proses evaluasi kedalam kriteria bobot keputusan dengan beberapa atribut pengambil keputusan [7]. Metode MOORA juga memiliki tingkat selektifitas yang baik karena dapat menentukan tujuan dan kriteria yang bertentangan, yaitu kriteria yang bernilai menguntungkan (Benefit) atau tidak menguntungkan (Cost). 
Berikut adalah flowchat perancangan penelitian:

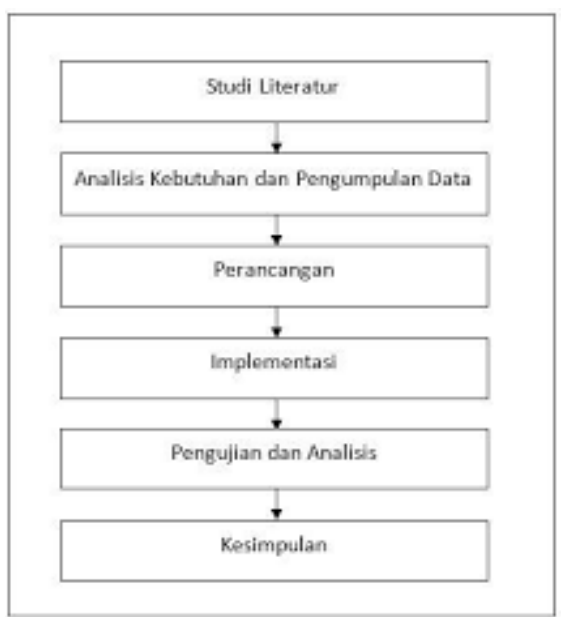

Gambar 1. Alur yang Diusulkan

Keterangan:

a) Melakukan pengumpulan data.

b) Melakukan PreProcessing data dengan memilih data-data pada penilaian kinerja tenaga pegawai honorer pada dinas ketenagakerjaan yang digunakan untuk data awal

c) Transformasi data dilakukan untuk mentransformasi atau mengubah data ke dalam bentuk yang dapat di proses dengan Moora.

d) Melakukan perhitungan dengan metode Moora secara tersetruktur

e) Melakukan perengkingan dari hasil perhitungan Moora

f) Menganalisa hasil dari perangkingan dari penilaian kinerja tenaga pegawai honorer pada dinas ketenagakerjaan.

\section{Hasil dan Pembahasan}

\subsection{Pembobotan}

Sebelum memasuki tahap analisis data, penulis terlebih dahulu melakukan praprocessing data yaitu dengan menentukan kriteria-kriteria yang akan dijadikan acuan dalam pengambilan keputusan dan memberikan bobot penilaian untuk setiap kriteria. Kriteria-kriteria dalam penelitian ini adalah seperti pada tabel 1.

Tabel 1. Kriteria dan tipe kriteria

\begin{tabular}{clc}
\hline Kriteria & Keterangan & Tipe \\
\hline C1 & Kehadiran & Benefit \\
C2 & Kualitas Kerja & Benefit \\
C3 & Disiplin Kerja & Benefit \\
C4 & Pelayanan & Benefit \\
\hline
\end{tabular}

Dari data kriteria dan pembobotan dari tabel diatas, penulis melakukan penyusunan kriteria berdasarkan nilai perioritas.Mulai dari kriteria dengan nilai bobot terendah hingga kriteria dengan nilai bobot tertinggi. Dalam menentukan nilai bobot dari masing-masing kriteria sudah ditetapkan untuk penliaian kinerja tenaga honorer pada dinas ketenagaan pematangsiantar. Untuk membuktikan bahwa data yang digunakan dalam penelitian ini adalah data yang valid. Adapun alternatif yang didapatkan dari study kasus penilaian honorer pada dinas ketenagakerjaan diantaranya sebagai berikut: 
Tabel 2. Data alternatif

\begin{tabular}{ccl}
\hline No. & Alternatif & \multicolumn{1}{c}{ Nama Alternatif } \\
\hline 1 & A1 & Line D. Simamora \\
2 & A2 & Sugianto \\
3 & A3 & Syahrizal \\
4 & A4 & Widya KS. Sitompul \\
5 & A5 & Sulastri Siahaan \\
6 & A6 & Ellyta Z. Saragih, SE \\
7 & A7 & Julianto P. Sembiring \\
\hline
\end{tabular}

Berdasarkan data yang diperoleh dari dinas ketenagakerjaan pematangsiantar, terdapat kriteria yang di tentukan pada penilaian kinerja honorer sebagai berikut:

Tabel 3. Data kriteria

\begin{tabular}{cccc}
\hline No. & \multicolumn{2}{c}{ Nama Kriteria } & Bobot \\
\hline 1 & C1 & Kehadiran & $35 \%$ \\
2 & C2 & Kualitas Kerja & $20 \%$ \\
3 & C3 & Disiplin Kerja & $20 \%$ \\
4 & C4 & Pelayanan & $25 \%$ \\
\hline
\end{tabular}

Kriteria yang memakai penilaian bukan nilai angka akan disesuaikan dengan skala penilaian seperti di bawah ini :

Tabel 4. Tingkat kepentingan

\begin{tabular}{ccc}
\hline No. & Keterangan & Nilai \\
\hline 1 & Sangat Baik & $90-100$ \\
2 & Baik & $70-80$ \\
3 & Cukup & $50-60$ \\
4 & Kurang & $<50$ \\
\hline
\end{tabular}

Pembobotan dari setiap kriteria:

Tabel 5. Pembobotan Daftar Kehadiran

\begin{tabular}{cc}
\hline Keterangan & Nilai \\
\hline Sangat Baik & $90-100$ \\
Baik & $70-80$ \\
Cukup & $50-60$ \\
Kurang & $<50$ \\
\hline
\end{tabular}

Tabel 6.Kualitas Kerja

\begin{tabular}{cc}
\hline Keterangan & Nilai \\
\hline Sangat Baik & $90-100$ \\
Baik & $70-80$ \\
Cukup & $50-60$ \\
Kurang & $<50$ \\
\hline
\end{tabular}

Tabel 7. Disiplin Kerja

\begin{tabular}{cc}
\hline Keterangan & Nilai \\
\hline Sangat Baik & $90-100$ \\
Baik & $70-80$ \\
Cukup & $50-60$ \\
Kurang & $<50$ \\
\hline
\end{tabular}

Tabel 8. Pelayanan

\begin{tabular}{cc}
\hline Keterangan & Nilai \\
\hline Sangat Baik & $90-100$ \\
Baik & $70-80$ \\
Cukup & $50-60$ \\
Kurang & $<50$ \\
\hline
\end{tabular}

Pada tabel 9. di bawah ini menunjukkan 7 data alternatif dari 7 orang pada penilaian kinerja tenaga honorer yang akan memenuhi persyaratan untuk pegawai honorer yang ada di dinas ketenagakerjaan pematangsiantar adalah sebagai berikut:

Tabel 9. Data Alternatif kriteria Penilaian Kinerja Tenaga Honorer

\begin{tabular}{clcccc}
\hline \multirow{2}{*}{ No } & \multicolumn{1}{c}{ Alternatif } & \multicolumn{4}{c}{ Kriteria } \\
\cline { 3 - 5 } & & Kehadiran & Kualitas Kerja & Disiplin Kerja & Pelayanan \\
\hline 1 & Line D. Simamora & Sangat Baik & Baik & Baik & Baik \\
2 & Sugianto & Baik & Baik & Baik & Baik \\
\hline
\end{tabular}




\begin{tabular}{llcccc}
\hline \multirow{2}{*}{ No } & \multicolumn{1}{c}{ Alternatif } & Kehadiran & Kualitas Kerja & Disiplin Kerja & Pelayanan \\
\cline { 3 - 5 } & & Sangat Baik & Baik & Baik & Baik \\
\hline 3 & Syahrizal & Baik & Baik & Baik & Cukup \\
4 & Widya KSSitompul & Baik & Cukup & Baik & Baik \\
5 & SulastriSiahaan & Baik & Baik & Cukup & Cukup \\
6 & Ellyta ZSaragih & Cukup & Cukup & Cukup & Cukup \\
7 & Julianto PSembiring & Cuk
\end{tabular}

Pada tabel 10 menjelaskan data konversi dari setiap arternatif pada kriteria yang telah ditentukan.

Tabel 10. Tabel Data Konversi

\begin{tabular}{lcccc}
\hline \multicolumn{1}{c}{ Alternatif } & \multicolumn{4}{c}{ Kriteria } \\
\cline { 2 - 5 } & C1 & C2 & C3 & C4 \\
\hline Line D. Simamora & 90 & 80 & 80 & 80 \\
Sugianto & 80 & 80 & 80 & 80 \\
Syahrizal & 90 & 80 & 80 & 80 \\
Widya KS. Sitompul & 80 & 80 & 80 & 60 \\
Sulastri Siahaan & 80 & 50 & 80 & 80 \\
EllytaZ.Saragih, SE & 80 & 80 & 50 & 60 \\
Julianto P. Sembiring & 60 & 50 & 50 & 60 \\
\hline
\end{tabular}

\subsection{Perhitungan Metode MOORA}

Setelah data dikonversi seperti yang tertera pada tabel 10, selanjutnya masuk kedalam proses perhitungan pada metode moora. Sebelumnya data diubah kedalam matriks keputusan menggunakan persamaan.

$X=\left[\begin{array}{llll}90 & 80 & 80 & 80 \\ 80 & 80 & 80 & 80 \\ 90 & 80 & 80 & 80 \\ 80 & 80 & 80 & 60 \\ 80 & 50 & 80 & 80 \\ 80 & 80 & 50 & 60 \\ 60 & 50 & 50 & 60\end{array}\right]$

Setelah membentuk matriks keputusan, selanjutnya masuk kedalam tahap ketiga yaitu normalisasi dengan menggunakan persamaan.

C1: Kehadiran

$$
\begin{aligned}
& \text { A1. } 1=\frac{90}{\sqrt{90^{2}+80^{2}+90^{2}+80^{2}+80^{2}+80^{2}+60^{2}}}=0,4223 \\
& \mathrm{~A} 2.1=\frac{80}{\sqrt{90^{2}+80^{2}+90^{2}+80^{2}+80^{2}+80^{2}+60^{2}}}=0,3754 \\
& \mathrm{~A} 3.1=\frac{90}{\sqrt{90^{2}+80^{2}+90^{2}+80^{2}+80^{2}+80^{2}+60^{2}}}=0,4223 \\
& \text { A4. } 1=\frac{80}{\sqrt{90^{2}+80^{2}+90^{2}+80^{2}+80^{2}+80^{2}+60^{2}}}=0,3754 \\
& 80 \\
& \text { A } 5.1=\frac{80^{2}+80^{2}+90^{2}+80^{2}+80^{2}+80^{2}+60^{2}}{\sqrt{90^{2}}}=0,3754 \\
& \text { A6. } 1=\frac{80}{\sqrt{90^{2}+80^{2}+90^{2}+80^{2}+80^{2}+80^{2}+60^{2}}}=0,3754 \\
& \text { A7. } 1=\frac{60}{\sqrt{90^{2}+80^{2}+90^{2}+80^{2}+80^{2}+80^{2}+60^{2}}}=0,2815
\end{aligned}
$$


Untuk mencari kriteria $\mathrm{C} 2, \mathrm{C} 3$, dan $\mathrm{C} 4$, menggunakan cara yang sama seperti pada $\mathrm{C} 1$. Maka diperoleh matriks normalisasi sebagai berikut;

$$
X=\left[\begin{array}{llll}
0,4224 & 0,3736 & 0,4120 & 0,4351 \\
0,3755 & 0,4270 & 0,4120 & 0,4351 \\
0,4224 & 0,4270 & 0,3605 & 0,4351 \\
0,3755 & 0,4270 & 0,4120 & 0,2720 \\
0,3755 & 0,2669 & 0,4120 & 0,3807 \\
0,3755 & 0,3736 & 0,3090 & 0,3264 \\
0,2816 & 0,3203 & 0,3090 & 0,3264
\end{array}\right]
$$

Selanjutnya mengoptimalisasi nilai atribut dengan mengalikan nilai dari setiap alternatif untuk masing-masing kriteria dengan bobot kriteria menggunakan persamaan.

$$
\begin{aligned}
& \text { C1: } \mathrm{W}=0,35 \\
& \text { A1. } 1=0,4223 * 0,35=0,1478 \\
& \text { A2. } 1=0,3754 * 0,35=0,1314 \\
& \text { A3. } 1=0,4223 * 0,35=0,1478 \\
& \text { A4. } 1=0,3754 * 0,35=0,1314 \\
& \text { A5. } 1=0,3754 * 0,35=0,1314 \\
& \text { A6. } 1=0,3754 * 0,35=0,1314 \\
& \text { A7. } 1=0,2815 * 0,35=0,0986
\end{aligned}
$$

Untuk mencari kriteria $\mathrm{C} 2, \mathrm{C} 3$ dan $\mathrm{C} 4$, menggunakan cara yang sama seperti pada $\mathrm{C} 1$. Maka diperoleh matriks normalisasi terbobot sebagai berikut;

$$
X=\left[\begin{array}{llll}
0,1478 & 0,0748 & 0,0825 & 0,1088 \\
0,1314 & 0,0855 & 0,0825 & 0,1048 \\
0,1478 & 0,0855 & 0,0722 & 0,1048 \\
0,1314 & 0,0855 & 0,0825 & 0,0786 \\
0,1314 & 0,0535 & 0,0825 & 0,1048 \\
0,1314 & 0,0748 & 0,0619 & 0,0786 \\
0,0986 & 0,0642 & 0,0619 & 0,0786
\end{array}\right]
$$

Selanjutnya mencari nilai y untuk memperoleh rangking dari setiap alternatif. Dapat dilihat pada tabel 11 .

Tabel 11. Nilai $Y$

\begin{tabular}{cccc}
\hline Alternatif & Maximun & Minimum & Yi \\
\cline { 2 - 4 } & $\mathbf{C 1 + C 2 + C 3 + C 4}$ & $\mathbf{0}$ & (Max-Min) \\
\hline A1 & 0,4139 & 0 & 0,4139 \\
A2 & 0,4042 & 0 & 0,4042 \\
A3 & 0,4103 & 0 & 0,4103 \\
A4 & 0,3780 & 0 & 0,3780 \\
A5 & 0,3722 & 0 & 0,3722 \\
A6 & 0,3467 & 0 & 0,3467 \\
A7 & 0,3033 & 0 & 0,3033 \\
\hline
\end{tabular}

Dan berikut adalah hasil perangkingan yang diperoleh dari nilai Y:

Tabel 12. Perangkingan

\begin{tabular}{cccc}
\hline No & Alternatif & Nilai Yi & Rangking \\
\hline 1 & A1 & 0,4139 & 1 \\
2 & A2 & 0,4042 & 3 \\
\hline
\end{tabular}




\begin{tabular}{cccc}
\hline No & Alternatif & Nilai Yi & Rangking \\
\hline 3 & A3 & 0,4103 & 2 \\
4 & A4 & 0,3780 & 4 \\
5 & A5 & 0,3722 & 5 \\
6 & A6 & 0,3467 & 6 \\
7 & A7 & 0,3033 & 7 \\
\hline
\end{tabular}

Berdasarkan hasil perhitungan menggunakan metode moora, maka alternatif yang dapat direkomendasikan yaitu alternatif ke-1 dengan nilai 0,4139 dan disusul dengan alternatif ke-3 dengan nilai 0,4103 .

\subsection{Implementasi}

Dalam implementasi sistem akan dibahas mengenai tampilan akhir antar muka sistem yang disesuaikan dengan perancangan sistem yang telah dibuat pada bab sebelumnya.

\section{a) Menu}

Menu digunakan sebagai indikator kepada pengguna agar dapat menjalankan program, dengan adanya menu dapat memudahkan dalam pencarian fasilitas suatu program yang sudah disediakan, sebelum masuk ke menu-menu dan sub menu user harus terlebih dahulu login agar dapat menjalankan sistem.

\section{Menu Login}

Padaform login ini berfungsi sebagai pengaman sistem atau disebut juga sebagai form kunci agar dapat masuk ke sistem. User harus menginput username danpassword dan klik login untuk bisa masuk kedalam sistem. Jika username dan password sesuai dengan sistem maka user dapat membuka sistem. Jika username dan password tidak sesuai maka user tidak dapat membuka sistem dan masuk kedalam halaman gagal login, untuk mengulang login klik login kembali pada halaman. Lihatgambar 2.

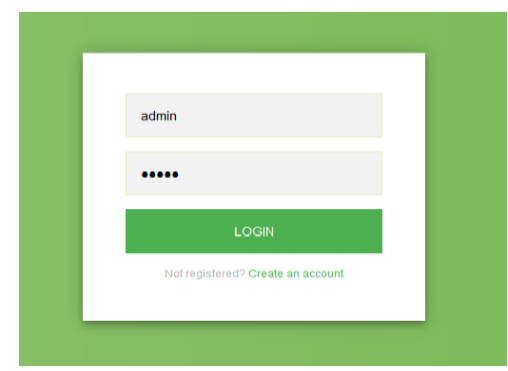

Gambar 2. Menu Login

2. Menu Utama

Form menu utama berisi menu-menu yang dapat dibuka oleh user. Pada form utama akan ditampilkan menu-menu pilihan (sub-menu) yang akan dijalankan sesuai keinginan user. Tampilan-tampilan halaman menu utama dapat dilihat pada gambar 3.

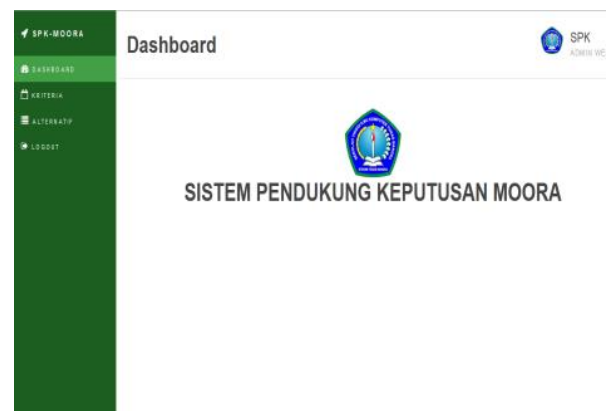

Gambar 3. Menu Utama 


\section{b) Keluaran (output) Sistem}

Pada gambar dibawah merupakan hasil dari perhitungan dengan menggunakan metode Moora.

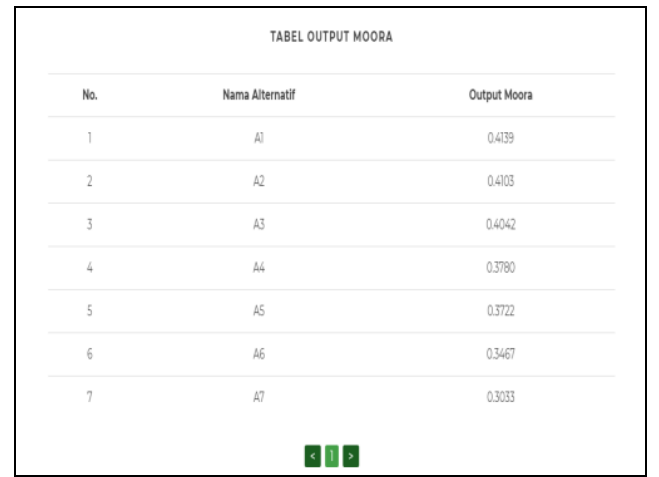

Gambar 4. Tabel Output

Pada gambar 4. tabel output dapat dijelaskan bahwa hasil dari output program terhadap penilaian kinerja pegawai honorer dan dapat dilihat setiap nama alternatif.

\section{Kesimpulan}

Hasil penilaian kinerja pegawai honorer yang terbaik mengalami peningkatan setelah analisis data perancangan dan perhitungan komputerisasi yang telah dilakukan, maka diperoleh kesimpulan dalam menentukan penilaian kinerja pada pegawai honorer antara lain :

a) Metode moora dapat menentukan suatu penilaian kinerja pegawai honorer yang terbaik pada sistem pendukung keputusan pada kantor dinas ketenagakerjaan kota pematangsiantar.

b) Proses pengujian data dalam sistem pendukung keputusan yang menggunakan metode moora memerlukan bobot kriteria sebagai penilaian suatu kinerja pada tenaga honorer.

c) Dalam menentukan kinerja pegawai honorer pada kantor dinas ketenagakerjaan kota pematangsiantar menggunkan metode moora dapat membantu mempermudah dalam menilai suatu kinerja pegawai

\section{Daftar Pustaka}

[1] Hidayatulloh, I. and Purwokerto, T. (2017) 'Metode Moora DenganPendekatan Price-Quality Ratio Untuk', pp. 62-68.

[2] Nuraini, R. (2015), 'Desain Algorithma Operasi Perkalian Matriks Menggunakan Metode Flowchart', 1(1), pp. 144-151.

[3] Ramadhani, W. W. (2017) 'Sistem Pendukung Keputusan Dalam Pemilihan Karyawan Terbaik Di PT. Smartlink Global Media Dengan Metode Weight

[4] Sarmadi, E. (2018), 'Pemilihan Kendaraan Roda Dua Menggunakan Metode Simple Additive Weighting (SAW) (Studi Kasus : PT . Sinar Sentosa)

[5] Satria, E. et al. (2018), 'SPK : Algoritma Multi-Attribute Utility Theory (MAUT) Pada Destinasi Tujuan Wisata Lokal DiKota Sidamanik', 3(2), pp. 168- 172.

[6] Sugiharto, L., Saptomo, W. L. Y. and Nugroho, D. (2017), 'Sistem Pendukung Keputusan Kinerja Tenaga Honorer Di Dinas Pekerjaan Umum Dan Energi Sumber Daya Mineral Kabupaten Klaten', Jurnal TIKomSiN, 5(2), pp. 7-13. doi: http://dx.doi.org/10.30646/tikomsin.v5i2.312.

[7] Windarto (2017), 'Penilaian Prestasi Kerja Karyawan PTPN III Pematangsiantar Dengan Metode Simple Additive Weighting ( SAW )’, 1), pp. 84-95. 